\title{
Antioxidant pre-treatments are able to reduce waiting time for restorative treatment after dental bleaching: a microtensile bond strength exploratory study
}

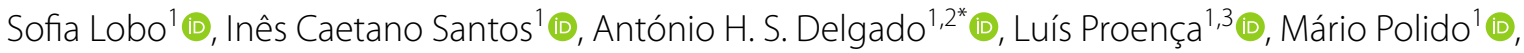 \\ Ana Mano Azul ${ }^{1}\left[\right.$ and José João Mendes ${ }^{1}$ (1)
}

${ }^{*}$ Correspondence:

aldelgado@egasmoniz.edu.pt

${ }^{1}$ Centro de Investigação Interdisciplinar Egas Moniz (CiiEM), Instituto Universitário Egas Moniz (IUEM), Campus Universitário, Quinta da Granja, Monte de Caparica, 2829-511 Caparica, Portugal Full list of author information is available at the end of the article

\begin{abstract}
The aim was to evaluate the effect of different antioxidant agents on the improvement of bond strength to enamel subjected to a whitening procedure. Samples were divided into six groups $(n=10)$ : control; whitening immediately followed by restorative treatment (WHT); whitening and restoration after a 7-day period (WHT_7D); whitening and application of 10\% sodium ascorbate (WHT_SA); application of 5\% grape seed extract (WHT_GS); and application of 5\% green tea (WHT_GT). All groups except for control fwere whitened (Opalescence PF Regular 16\%) for 7 days (4 h/day). All samples were restored (Optibond ${ }^{\mathrm{TM}} \mathrm{FL}$, Kerr and Filtek ${ }^{\mathrm{TM}} \mathrm{Z} 250$ composite, 3M ESPE). In antioxidant groups these were applied for $15 \mathrm{~min}$ and immediately restored. Specimens were sectioned in microspecimens ( $1.0 \pm 0.2 \mathrm{~mm}^{2}$ area) for microtensile bond strength ( $\mu$ TBS) testing $(0.5 \mathrm{~mm} / \mathrm{min})$ on a universal testing machine. ANOVA test with Brown-Forsythe correction and Games-Howell post-hoc test was used (significance level of 5\%). Antioxidant groups presented significant higher mean $\mu$ TBS values than group WHT $(p<0.001)$. The non-whitened control group was not significantly different to antioxidant experimental groups. Group WHT_7D exhibited a significantly higher mean $\mu$ TBS value when compared to group WHT ( $p=0.022)$. The different antioxidants significantly influenced microtensile bond strength of restored teeth after whitening.
\end{abstract}

Keywords: Antioxidant, Bond strength, Dental bleaching, Dental whitening, Sodium ascorbate, Grape seed extract, Green tea

\section{Introduction}

Due to an increase in patient awareness and search for aesthetic treatments, dental whitening has become a frequent, safe and conservative procedure. It has an ability to remove stains and to whiten discoloured teeth in need of aesthetic improvement [1-3]. However, whitening procedures are known to reduce bond strength of dental adhesives to enamel and dentin. Whitening agents generate free radicals and reactive oxygen species, a subproduct of the reaction, which remain on the tooth surface. These subproducts

(c) The Author(s) 2021. This article is licensed under a Creative Commons Attribution 4.0 International License, which permits use, sharing adaptation, distribution and reproduction in any medium or format, as long as you give appropriate credit to the original author(s) and the source, provide a link to the Creative Commons licence, and indicate if changes were made. The images or other third party material in this article are included in the article's Creative Commons licence, unless indicated otherwise in a credit line to the material. If material is not included in the article's Creative Commons licence and your intended use is not permitted by statutory regulation or exceeds the permitted use, you will need to obtain permission directly from the copyright holder. To view a copy of this licence, visit http://creativeco mmons.org/licenses/by/4.0/. 
in turn can neutralize the free-radicals generated during the addition polymerisaiton reaction of resin monomers, inhibiting it and interfering with the infiltration of the resin phase during the bonding procedure [4-8]. Thus, bond strength to whitened enamel or dentin, immediately after the procedure, is suboptimal.

The organic pigments responsible for affecting colour of the dental structure are compounds named chromogens, which are retained in enamel due to its semipermeable matrix. These are stained molecules composed of conjugated double bonds. Dental whitening oxidizes these molecules, turning them into colourless compounds. This happens by breaking one or more double bonds within this conjugate system $[9,10]$. The active bleaching agent in dental whitening procedures is hydrogen peroxide $\left(\mathrm{H}_{2} \mathrm{O}_{2}\right)$, which can also be obtained from the conversion of carbamide peroxide, a solid urea peroxyhydrate solution. Due to its low molecular weight, it has a diffusion capability and can readily penetrate enamel and dentin. Theses tissues act as semipermeable membranes, allowing molecules to diffuse through interprismatic spaces and dentinal tubules, where they interact with organic chromogens, generating free radicals [1, 9-11]. The bond breakage reaction results in smaller (lower molecular weight), less pigmented and hydrophilic molecules. These changes are able to alter their light absorption spectrum also leading to differences in their optical parameters and perception $[10,12,13]$.

Dissociation of hydrogen peroxide creates a very reactive hydroxyl radical, which in turn can oxidize free radicals generated by polymerisation initiators, turning them into stable species that are then unable to react with dental monomers, inhibiting polymerisation $[14,15]$. Differences in resin tag formation such as frail tags and susceptibility to adhesive failure has also been reported in teeth that were bleached. $\mathrm{Ca} / \mathrm{P}$ content of the mineral phase also seems to be affected after whitening procedure [16-18]. Such events lead to lower bond strengths of immediately restored teeth that have been whitened. Incomplete polymerisation processes of the adhesive or resin composite affects the final properties of the polymer, impacting the physico-mechanical properties of the restoration [19]. This reduction of bond strength may affect the longevity of the restorative treatment $[20,21]$. To avoid a compromise of bond strength, a waiting time of one to 3 weeks before any restorative treatment, is recommended, as oxygen species decay over time. This period also allows enamel remineralization by saliva. However, this waiting time is not clinically desirable or feasible in most cases [7, 8, 22].

Antioxidant agents, such as sodium ascorbate, green tea, grape seed extract, aloe vera, tocopherol or sodium bicarbonate have shown promising results as reversers of these temporary adverse effects caused during whitening and as an alternative to waiting. Antioxidant agents are capable of neutralizing reactive species and have the potential to act in different stages of their formation. Thus, when used after whitening and before the restorative procedure, antioxidants can restore the bond strength to enamel, that had been compromised [2, 6, 22-25]. This strategy is dependent upon factors such as antioxidant type, concentration and application time, and further research is warranted [26, 27].

A quick and easy to use solution is then needed to overcome the effects of whitening on dental surfaces, allowing immediate, uncompromised treatment. It is therefore important to investigate conventional antioxidants, at low concentrations, that can be easily acquired and prepared and eventually adopted in a clinical setting. Such strategies 
Table 1 Materials used in this study according to source, composition and batch, based on information supplied by the manufacturers, safety datasheets and solutions prepared in laboratory

\begin{tabular}{|c|c|c|c|}
\hline Product & Manufacturer & Composition & Batch \\
\hline Filtek $^{\mathrm{TM}} \mathrm{Z} 250$ (A3 color) & 3M ESPE, USA & $\begin{array}{l}\text { Bis-GMA, UDMA, TEGDMA, Bis- } \\
\text { EMA, zirconia and silica filler } \\
\text { particles ( } 60 \text { wt } \%)\end{array}$ & NA13481 \\
\hline $\begin{array}{l}\text { Grape seed extract (100 mg } \\
\text { vegetable capsules) }\end{array}$ & Solgar Inc., USA & $\begin{array}{l}\text { Microcrystalline cellulose and vitis } \\
\text { vinifera extract containing } 90 \% \\
\text { polyphenols }\end{array}$ & 223113-05 \\
\hline $\begin{array}{l}\text { Green tea sachets } \\
\text { (Tetley Green Tea Classic) }\end{array}$ & Tata Global Beverages GB Ltd. UK & $\begin{array}{c}\text { Green tea leaves containing } \\
0.62 \mathrm{mg} / \mathrm{mL} \text { of flavanoids }\end{array}$ & 191693 \\
\hline 16\% Opalescence PF Regular & Ultradent Products, USA & $\begin{array}{l}\text { 16\% carbamide peroxide, potas- } \\
\text { sium nitrate, sodium fluoride } \\
\text { and water }\end{array}$ & BGP3 \\
\hline \multirow[t]{2}{*}{ Optibond $^{\mathrm{TM}} \mathrm{FL}$} & \multirow[t]{2}{*}{ Kerr, Italy } & $\begin{array}{l}\text { Primer: HEMA, GPDM, MMEP, } \\
\text { ethanol, water and initiators }\end{array}$ & \multirow[t]{2}{*}{6732914} \\
\hline & & $\begin{array}{l}\text { Adhesive: Bis-GMA, HEMA, GDMA, } \\
\text { barium aluminosilicate, sodium } \\
\text { hexafluorosilicate and fumed } \\
\text { silica, initiators }\end{array}$ & \\
\hline Placebo gel & Fabricated at IUEM, Portugal & $\begin{array}{l}93.8 \% \text { water, } 5 \% \text { glycerine and } \\
1.2 \% \text { carbopol }\end{array}$ & - \\
\hline Scotchbond ${ }^{\mathrm{TM}}$ Etchant & 3M ESPE, USA & $\begin{array}{l}\text { Water, 34\% ortophosphoric acid, } \\
\text { polyethylene glycol, synthetic } \\
\text { amorphous silica, aluminium } \\
\text { oxide }\end{array}$ & 4785595 \\
\hline Sodium ascorbate & Fabricated at IUEM, Portugal & $\begin{array}{l}\text { Sodium ascorbate } 10 \% \text {, carbopol } \\
934(2.5 \%) \text { and triethanolamine } \\
(\mathrm{pH}=7)\end{array}$ & - \\
\hline
\end{tabular}

$\mathrm{pH}$ values were measured using a bench $\mathrm{pH}$ meter (Crison Basic $20+$, Crison Instruments, Spain)

Bis-GMA bisphenol-A-glycidyl dimethacrylate, GDMA glycidyl dimethacrylate, GPDM glycerophosphate dimethacrylate, HEMA hydroxy ethyl methacrylate, N/A not available in the information supplied, MMEP mono(2-methacryloyloxy) ethyl phthalate, TEGDMA triethylene glycol dimethacrylate, UDMA urethane dimethacrylate

should also be compared and validated against a waiting period, in order to determine their efficacy. The aim of this laboratory exploratory study is to evaluate the effect of different regular antioxidant agents on the microtensile bond strength to enamel after an "at-home" whitening procedure. The null hypothesis is that the microtensile bond strength ( $\mu \mathrm{TBS}$ ) of teeth restored after whitening is not affected by a pre-surface treatment with a low concentration (5\%) of sodium ascorbate, grape seed extract or green tea.

\section{Methods}

Thirty sound human permanent molars, extracted for orthodontic or periodontal reasons, obtained from the Biobank at Instituto Universitário Egas Moniz (IUEM), with Ethics Approval (Egas Moniz Ethics Commission-Internal Process 691) were selected for the present study.

Before preparation, teeth were cleaned by removing soft tissues and debris using periodontal curettes and were stored in a solution of $1 \%$ chloramine $\mathrm{T}$, for less than a week. Then they were placed in deionized water at a temperature of $4{ }^{\circ} \mathrm{C}$ until they were used, replenished weekly, according to ISO/TS 11405:2015. The materials used in this study are shown in Table 1. 


\section{Sample preparation}

Teeth were cut at $0.125 \mathrm{~mm} / \mathrm{min}$ in a low-speed, water cooled, hard tissue microtome (Accutom-50, Struers) in order to obtain two identical sample halves, buccal and lingual, which were the experimental unit in this study, originating 60 samples.

Samples were further randomly divided in six groups $(n=10)$ :

- Control-control group, without whitening agent and antioxidant agent;

- WHT-whitening procedure followed by a restoration immediately after;

- WHT_7D-whitening procedure followed by a restoration performed after a waiting period of 7 days;

- WHT_SA - whitening followed by application of $10 \%$ sodium ascorbate for $15 \mathrm{~min}$;

- WHT_GS - whitening followed by application of 5\% grape seed extract for $15 \mathrm{~min}$.

- WHT_GT-whitening followed by application of 5\% green tea for $15 \mathrm{~min}$.

To delimitate an identical surface area for the whitening procedure, antioxidant treatment and bonding/restoration, samples were fixated onto a calibrated stainless-steel jig with four $10 \times 5 \times 6 \mathrm{~mm}$ windows, through which materials were applied. All samples from whitening groups were submitted to a whitening gel treatment of $16 \%$ carbamide peroxide (Opalescence PF Regular 16\%, Ultradent Products, South Jordan, USA) applied according to manufacturer's instructions, and, in the control group, a placebo gel (IUEM, $1.2 \%$ carbopol, $93.8 \%$ water and $5 \%$ glycerine) was applied. Approximately $0.1 \mathrm{~mL}$ of gel were respectively applied for four hours. During the four hours of the whitening agent or placebo contact gel, samples were in an incubator at $37^{\circ} \mathrm{C}$ (Memmert INE 400). Samples were then cleaned with a sterile gauze and deionized water. Whitening and placebo gels were applied every day, once a day, for a total period of 7 days. In between the procedures, samples were stored in artificial saliva, prepared following a previously published protocol [28], in an incubator at $37^{\circ} \mathrm{C}$.

\section{Application of the antioxidant agents}

Immediately after the whitening procedure completion, experimental groups WHT_SA, WHT_GS and WHT_GT were subject to application of 10\% of sodium ascorbate gel, 5\% of grape seed extract solution or $5 \%$ of green tea solution, respectively, for $15 \mathrm{~min}$. Application of $0.25 \mathrm{~mL}$ of solution in each corresponding experimental group was carried out with a disposable pipette through the delimitated jig windows, mentioned above. Green tea $(\mathrm{pH}=5.41)$ and grape seed extract $(\mathrm{pH}=5.92)$ solutions were prepared by dissolving $5 \mathrm{~g}$ of each extract in $100 \mathrm{~mL}$ of water. After the application time elapsed, tooth surfaces were rinsed with deionized water and cleaned using a sterile gauze.

\section{Bonding and restorative procedure}

All groups were subject to smear layer simulation, by polishing the enamel surface, using $600 \mathrm{SiC}$ grit paper (Buehler Ltd, Lake Bluff, IL, USA) for $60 \mathrm{~s}$, under water cooling, using an automatic polishing machine operating at $100 \mathrm{rpm}$ (LaboPol-4, Struers, Denmark).

The bonding procedure was subsequently carried out with an etch-and-rinse bonding system (Optibond ${ }^{\mathrm{TM}}$ FL, Kerr, Scapati, Italy). All samples were etched with 
orthophosphoric acid (Scotchbond $^{\mathrm{TM}}$ Etchant, 3M ESPE, St. Paul, USA) at 34\% for $15 \mathrm{~s}$, rinsed and dried, according to manufacturer's instructions, then the primer was applied for $15 \mathrm{~s}$ and air dried for $5 \mathrm{~s}$; and using the same applicator, the adhesive was applied and brushed for $15 \mathrm{~s}$. A $20 \mathrm{~s}$ light-curing cycle was performed using an LED light-curing unit at $1330-1470 \mathrm{~mW} / \mathrm{cm}^{2}$ power output (Elipar ${ }^{\mathrm{TM}}$ DeepCure-S, 3M ESPE, St. Paul, USA). A microhybrid resin composite (Filtek ${ }^{\mathrm{TM}}$ Z250, 3M ESPE, St. Paul, USA), A3 shade, was then placed in $2 \mathrm{~mm}$ increments, at a maximum height of $6 \mathrm{~mm}$ and polymerized for a period of $40 \mathrm{~s}$. For each $2 \mathrm{~mm}$ layer, a $20 \mathrm{~s}$ light-curing cycle was performed with the parameters above described.

Samples from groups WHT, WHT_SA, WHT_GS, WHT_GT and the control group were immediately restored. WHT_7D group was stored after whitening, for 7 days, in an artificial saliva solution and stored in an incubator at $37^{\circ} \mathrm{C}$ (Memmert INE 400, Menmert, Germany). They were accordingly restored after the waiting period.

\section{Microtensile bond strength test ( $\mu$ TBS)}

After $24 \mathrm{~h}$ elapsed, following the restorative procedure, specimens were mounted on jigs and sectioned in $\mathrm{x}$ and $\mathrm{y}$ axis direction by a diamond saw at low speed, under water cooling (Accutom-50, Struers), originating, on average, 7 beams per sample (70 per experimental group), with cross-sectional areas of $1.0 \pm 0.2 \mathrm{~mm}^{2}$. All enamel beams considered viable were measured using a digital caliper (Storm Digital Caliper, Pontoglio, BS, Italy) to $0.001 \mathrm{~mm}$. These microspecimens were attached to Geraldeli type jigs and further submitted to tensile stress until failure using a universal testing machine (Shimadzu Autograph AG-IS, Kyoto, Japan) with a load cell of $1 \mathrm{kN}$, at $0.5 \mathrm{~mm} / \mathrm{min}$ of crosshead speed. Microtensile bond strength $(\mu T B S)$ results were expressed in megapascal (MPa) and calculated using the following equation: $\mu T B S(M P a)=\frac{F}{A}$, where $\mathrm{F}$ is the maximum force required for microspecimens to fracture, expressed in $\mathrm{kN}$, and $\mathrm{A}$ is the area expressed in $\mathrm{mm}^{2}$.

Fractographic analysis was carried out using a light stereomicroscope (Leica ATC 2000, USA) at $20 \times$ magnification. Failures were classified and registered as adhesive (at the adhesive interface), cohesive (at the composite or at enamel) and mixed (at the composite and enamel). Pre-test failures were counted as $0 \mathrm{MPa}$. Microtensile bond strength testing was done in accordance with the guidelines set out by the Academy of Dental Materials [29].

\section{Statistical analysis}

Statistical analysis was performed with statistical software IBM SPSS Statistics, version 25.0 for Windows (IBM Corporation, Armonk, USA). To compare the mean values of microtensile bond strength, a statistical inference analysis was conducted by using the ANOVA test with Brown-Forsythe correction, followed by a multiple comparison analysis by the Games-Howell post-hoc test. Prior verification of homoscedasticity and data normality was performed. A significance level of $5 \%$ was set for all inferential analysis. The sample size was calculated in $\mathrm{G}^{*}$ Power 3.1, for a power of $80 \%$ and alpha error probability of $5 \%$, by estimating the effect size from $\mu$ TBS means, based on the results of a pilot study. 
Table 2 Microtensile bond strength (MPa) mean values (M) for each group, correspondent standard deviation (SD) and 95\% confidence interval for mean (95\% Cl)

\begin{tabular}{lllr}
\hline Experimental groups & $n$ & \multicolumn{1}{l}{$\begin{array}{l}M T B S \\
M( \pm S D)\end{array}$} & {$[95 \% \mathrm{Cl}]$} \\
\hline Control & 10 & $18.2( \pm 2.6)^{\mathrm{A}}$ & {$[16.3-20.0]$} \\
WHT & 10 & $9.4( \pm 0.9)^{\mathrm{B}}$ & {$[8.8-10.1]$} \\
WHT_7D & 10 & $14.7( \pm 1.5)^{\mathrm{C}}$ & {$[13.6-15.7]$} \\
WHT_SA & 10 & $17.4( \pm 2.5)^{\mathrm{AC}}$ & {$[15.6-19.2]$} \\
WHT_GS & 10 & $15.3( \pm 2.5)^{\mathrm{AC}}$ & {$[13.5-17.1]$} \\
WHT_GT & 10 & $16.5( \pm 1.7)^{\mathrm{AC}}$ & {$[15.3-17.7]$} \\
\hline
\end{tabular}

Different capital letters indicate significant differences (Games-Howell post-hoc test, $p<0.05$ )

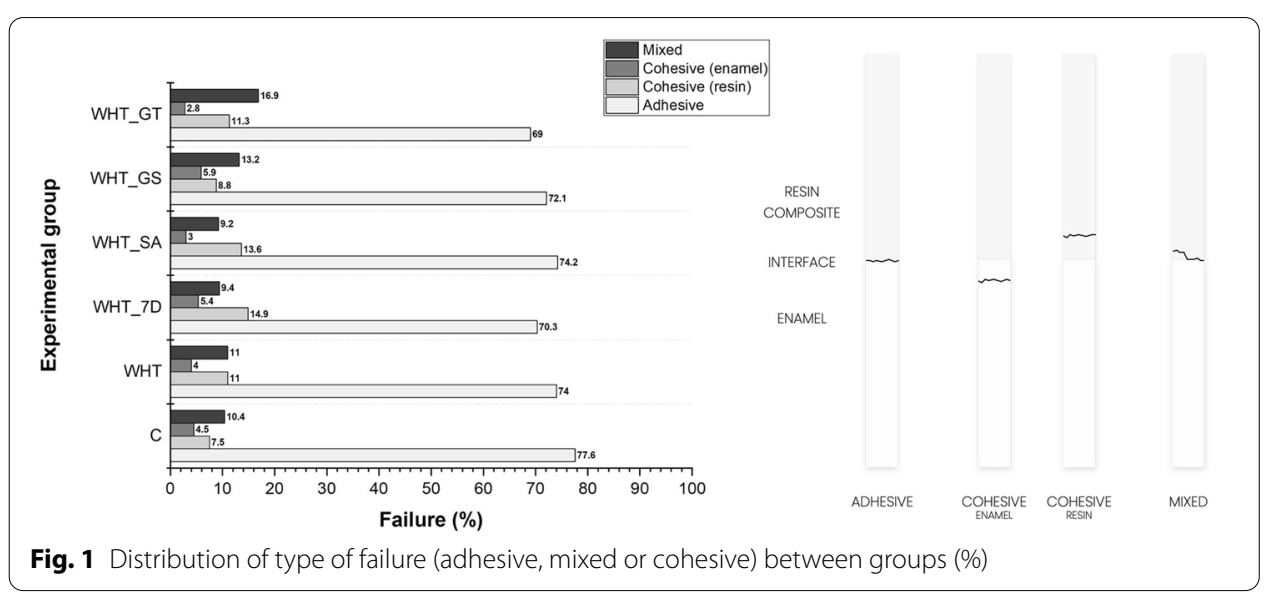

\section{Results}

Microtensile bond strength means, standard deviations and correspondent $95 \%$ confidence intervals $(95 \% \mathrm{CI})$ for means are summarized in Table 2. The distribution of type of failure (adhesive, mixed or cohesive) among groups is represented in Fig. 1. All groups showed predominance of adhesive failures, while WHT_7D and WHT_SA also showed a relatively high percentage of cohesive failures in resin, following the adhesive failures.

When comparing $\mu \mathrm{TBS}$ values of the different groups, it is possible to find significant differences between: the group subjected only to dental whitening (WHT) and the control group (18.2 $( \pm 2.6) \mathrm{MPa}), p<0.001$; the group subjected only to dental whitening (WHT) and the group in which restoration was performed after 7 days (WHT_7D) (14.7 $( \pm 1.5) \mathrm{MPa}), p<0.001$; the group subjected only to dental whitening (WHT) and the groups in which the antioxidants (WHT_SA, WHT_GS and WHT_GT) were applied (17.4 $( \pm 2.5) \mathrm{MPa} ; 15.3( \pm 2.5) \mathrm{MPa} ; 16.5( \pm 1.7) \mathrm{MPa}$, respectively), $p<0.001$. Moreover, despite there being an improvement of bond strength after a 7-day waiting period (WHT_7D) these results were still different to the control group which was not bleached, $(p=0.022)$.

However, no significant differences were observed between the control group and the groups to which the antioxidants were applied before the adhesive procedure: sodium ascorbate (WHT_SA), $p=0.980$; grape seed extract (WHT_GS), $p=0.159$; green tea (WHT_GT), $p=0.526$. Between the three experimental strategies, the antioxidants did 
not show differences in immediate bond strength results, with all being similar $(p>0.05)$, even despite WHT_SA having a higher value than WHT_GS and WHT_GT. Analysing the confidence intervals, WHT_SA was close to being statistically higher, and marginally significant to a 7-day waiting period, but did not show differences.

\section{Discussion}

Restorative adhesive procedures are commonly performed after whitening, such as in cases where patients have restorations performed prior to the procedure which have a different final colour; in combination with comprehensive oral rehabilitation such as ceramic/composite veneers or in the event of orthodontic bracket adhesion [6, 30,31]. It is therefore required to research techniques and ways to improve the depleted bond strength in bleached substrates.

Hydroxyl radicals present in the hydroxyapatite crystal network are replaced by peroxide ions during whitening, resulting in the formation of apatite peroxide. Therefore, waiting a period between whitening and restorative procedure is recommended, as after 1-3 weeks there is ion dissociation and hydroxyl radicals re-entry the apatite crystal lattice, eliminating the structural changes caused by incorporating these peroxide ions [5-8, 13, 32]. A surface pre-treatment with antioxidant agents such as sodium ascorbate, grape seed extract and green tea, used in this study, has however, shown potential to counteract the negative effects of hydrogen peroxide byproducts $[6,8,33]$. Lattice substitutions are thermodynamically unstable, favouring the theory of antioxidant reversal ability [34]. Some authors argue that it may take more than 21 days to restore enamel's mechanical properties, as fracture behaviour changes after whitening [35].

As seen in this study, a restoration placed immediately after bleaching presented the lowest bond strength results and is also in agreement with what is suggested by several studies. Whitening agents directly affect adhesive performance to enamel, since the production of oxygen subproducts is able to compete with the free radicals generated during a light-activated polymerization reaction $[5,13,36]$. A decrease in the degree of conversion, measured in restorations performed immediately after bleaching has been documented, and this is also responsible for the reduction of bond strength results, producing weaker hybrid layers $[37,38]$. In addition, it has been shown that resin penetration may also be impaired in bleached teeth, with less monomer infiltration being described, due to surface alterations imposed by residual peroxide. Increased density of voids and spherical defects at the adhesive interface in enamel have also been reported. [34] This may also be related to porosity and alterations to the hydroxyapatite prisms with depletion of the calcium-phosphate ratio [39].

A 7-day waiting period compared to an immediate rehabilitation was also found in this study to increase bond strength results. This is because, as previously described, oxygen reactive species have delayed release and also tend to decay in quantity over time [40]. Additionally, in vivo exposure of whitened teeth to saliva may help restore bond strength values, since saliva has alternative antioxidants and also promotes a remineralization effect important for mechanical properties [36]. However, this waiting time may not be clinically desirable as it precludes immediate continuation of other restorative procedures [8] and may not be sufficient time to fully improve bond strength results, to the point of a non-whitened surface, as seen in the results of the present study. 
Interestingly, for the groups to which the antioxidants were applied, they showed better results when compared to the group that was subject to a waiting period; however, these results were not statistically significant. Thus, it is possible to verify, as in several studies, that the application of antioxidants can be considered as a very viable alternative to the waiting time, regarding its potential to reverse the temporary adverse effects caused by the whitening agents $[2,4,6,24]$. The bond strength values of the groups to which the antioxidants were applied were similar to the values reported in the control group, which means that the application of sodium ascorbate, grape seed extract and green tea may in fact restore baseline values, similar to those of a tooth that was not whitened. Based on these results, antioxidants may be thus able to fully restore the redox potential that had been changed due to the presence of oxygen free radicals on the enamel surface $[22,23,41,42]$. Other strategies such as enamel surface reduction of $0.5 \mathrm{~mm}$ have also been proposed, especially in teeth which have the indication for indirect preparations, and this showed good results [43]. This backs up the hypothesis of a surface effect related to the presence of inhibitory reactive oxygen species.

The highest bond strength results in this study, statistically significant, were found in the groups subjected to whitening followed by sodium ascorbate, grape seed extract and green tea application, in comparison to whitening only, further confirming a neutralization of reactive oxygen species $[4,6-8,13]$. Antioxidants have also been documented to promote remineralization of the enamel after bleaching, as remineralization is directly proportional to neutralization of reactive oxygen species by antioxidants [38]. Curiously, a higher number of cohesive failures in resin composite were seen in the group subjected to a delayed restoration and in the group which received $10 \%$ sodium ascorbate. These are generally linked to higher bond strength values, since the material itself failed before the adhesive interface, indicating bond strength may be even higher than reported. This may also favour the use of sodium ascorbate over other antioxidants, proving its antioxidant ability by strengthening the adhesive interface.

The three antioxidants showed similar performance. Although there are still few studies in the literature using antioxidants from natural sources (i.e., grape seed extract and green tea), they have shown that they can be used as an alternative to sodium ascorbate, which has already been included in a considerable number of published studies [2, 8, $24,44]$. It is important to point out that rhombohedral crystal depositions occur after sodium ascorbate application in bleached enamel, but these are likely to be removed with thorough water rinsing, favouring their dissolution [34].

Antioxidants from natural sources are widely used in several therapeutic medical applications and dietary supplements. Antioxidants such as grape seed extract may contain oligomeric proanthocyanin complexes (OPCs). They can also contain polyphenols, which are also present in the dried leaves of green tea. Catechins, belonging to the polyphenol family, especially epigallocatechin gallate (EGC), is the most studied and active catechin, with a strong antioxidant effect [45]. The green tea used in this study contained $\sim 64 \%$ catechins, in line with solutions used in previous studies [46]. Sodium ascorbate, commonly known as vitamin $\mathrm{C}$, may neutralize the effects of residual oxygen by allowing free radical free polymerization of the resin composite. OPCs present in grape seed extract, and polyphenols present in green tea through the hydroxyl group, are able to donate hydrogens, which bind to free radicals, neutralizing them $[7,8,44]$. This 
explains their antioxidant potential. Grape seed extract has an almost-immediate effect on reverting bond strength reduction at a concentration equal and above that of 5\% [47]. Allegedly, OPCs have 20 times the antioxidant capacity of sodium ascorbate [48]. Furthermore, OPCs are known to provide strong antioxidant effect to counter the action of $\mathrm{NaOCl}$ treatment in dentine, and fully reverse surface adverse effects caused by oxygen species. They were effective at $5 \%$ for more than $5 \mathrm{~min}$, or at $10 \%$ or $15 \%$ for more than 1 min [49]. Parameters such as molecular weight and dissolution capacity of the antioxidants should be taken into consideration, as these account for variability between results of different antioxidants and have been proven to play a role [50]. This claimed antioxidant capacity and immediate bond strength improvement proven in vitro, should however be investigated and verified in clinical studies.

The results seen in this study are also concordant with results obtained micro-shear bond strength data from Elawsya et al. [51] even though these authors tested higher concentrations of carbamide peroxide/hydrogen peroxide and also of the antioxidants in this present study. The concentration of the whitening agent used is also relevant, as this varies the reduction in bond strength obtained $[44,51]$. Other than the concentration, the $\mathrm{pH}$ is also important in determining demineralization potential of enamel. The whitening agent used in this study has a reported $\mathrm{pH}$ in the range of 7 and is not expected to cause demineralization of the substrate [38]. The intactness of enamel surface morphology is controlled by the $\mathrm{pH}$ of the agent used [50].

According to the results of this study, the null hypothesis should be rejected, as significant differences in the bond strength of restorations in bleached teeth have been demonstrated with the use of sodium ascorbate, green tea and grape seed extract.

Considering the limitations of these results, 15 min application of antioxidants may be clinically undesirable, thus stronger concentrations with reduced application times require further research. Grape seed extract and green tea are solutions that have a staining potential. The possibility of a staining effect is however unlikely, given that this protocol is a one-time application for a very short time frame. Nonetheless, previous studies seem to indicate color stability is maintained [45, 52]. Antioxidants such as grape seed extract containing OPCs and baicalein, are also used in adhesive dentistry as collagen cross-linkers and matrix metalloproteinase (MMPs) inhibitors, to control and prevent hybrid layer breakdown. In fact, OPCs are known to induce crosslinking via a hydroxylation reaction to proline, in collagen of dentine [49]. Additionally, EGC prevenient from natural extracts also has stabilization properties of the adhesive interface, due to collagen biomodification and degradation reduction. New adhesives and dental composites containing antioxidants as organic matrix components are currently being researched and may constitute an interesting approach with multiple applications.

Considering all the published studies that have used antioxidants as restorers of compromised bond strength, it is up to the clinician to decide which technique should be advocated. Such strategies should also be implemented in the whitening regime, and maybe incorporated as part of the treatment in the future $[2,5]$. 


\section{Conclusions}

Based on the finding from this study, taking into account limitations related to the in vitro study model, it is possible to infer that the application of conventional and easy preparation antioxidants such as sodium ascorbate, grape seed extract and green tea were all able to immediately increase the bond strength to enamel subject to a dental whitening procedure. Bond strengths after such antioxidant strategies were comparable to non-whitened control and to a 7-day waiting period. This study highlights there may be an advantage in the use of antioxidants by the clinician, decreasing the waiting period until the restorative procedure, eliminating the need for a treatment plan delay, and can serve as a starting point for clinical studies. Furthermore, the antioxidant choice can be tailored according to its properties, advantages, disadvantages, and long-term results, subject to future studies, since no differences were found between the antioxidants used, in what concerned immediate bond strength outcomes.

\section{Acknowledgements \\ The authors acknowledge Cooperativa de Ensino Superior Egas Moniz Crl., for the materials supplied for the accomplish- ment of this research project.}

\section{Authors' contributions}

SL was involved in the design, acquisition of data, writing and revising the manuscript. IC participated in the conception and supervision of the investigation, analyzed the data and was involved in drafting and revising the manuscript. AD was involved in data curation, interpretation, drafting and revision of the manuscript. LP was involved in the statistical analysis, data interpretation and revision of the manuscript. MP was involved in the supervision of the data acquisition, analysis and revision of the manuscript. AA was involved in data analysis, interpretation and revised the manuscript, while JJM was involved in the conception, design of the investigation, data analysis and manuscript revision. All authors made significant contributions to the manuscript and have approved its submission. All authors read and approved the final manuscript.

\section{Funding}

This study did not receive any funding.

\section{Availability of data and materials}

The datasets used and/or analysed during the current study are available from the corresponding author on reasonable request.

\section{Declarations}

Competing interests

No potential competing interest was reported by the authors.

\section{Author details}

${ }^{1}$ Centro de Investigação Interdisciplinar Egas Moniz (CiiEM), Instituto Universitário Egas Moniz (IUEM), Campus Universitário, Quinta da Granja, Monte de Caparica, 2829-511 Caparica, Portugal. ${ }^{2}$ Division of Biomaterials and Tissue Engineering, UCL Eastman Dental Institute, University College London, Royal Free Hospital NW3 NPF, London, UK. ${ }^{3}$ Quantitative Methods for Health Research (MQIS), CiiEM, IUEM, Caparica, Portugal.

Received: 24 March 2021 Accepted: 24 May 2021

Published online: 31 May 2021

\section{References}

1. Rodríguez-Martínez J, Valiente M, Sánchez-Martín MJ. Tooth whitening: from the established treatments to novel approaches to prevent side effects. J Esthet Restor Dent. 2019;31:431-40. https://doi.org/10.1111/jerd.12519.

2. Feiz A, Mosleh $\mathrm{H}$, Nazeri R. Evaluating the effect of antioxidant agents on shear bond strength of tooth-colored restorative materials after bleaching: a systematic review. J Mech Behav Biomed Mater. 2017;71:156-64. https:// doi.org/10.1016/j.jmbbm.2017.03.010.

3. Naidu AS, Bennani V, Aarts JM, Brunton P. Over-the-counter tooth whitening agents: a review of literature. Braz Dent J. 2020;31:221-35. https://doi.org/10.1590/0103-6440202003227.

4. Dabas D, Patil AC, Uppin VM. Evaluation of the effect of concentration and duration of application of sodium ascorbate hydrogel on the bond strength of composite resin to bleached enamel. J Conserv Dent. 2011;14:35660. https://doi.org/10.4103/0972-0707.87197. 
5. Vidhya S, Srinivasulu S, Sujatha M, Mahalaxmi S. Effect of grape seed extract on the bond strength of bleached enamel. Oper Dent. 2011;36:433-8. https://doi.org/10.2341/10-228-L.

6. De Carvalho HC, Guiraldo RD, Poli-Frederico RC, Maciel SM, Moura SK, Lopes MB, et al. Correlation between antioxidant activity and bonding strength on bleached enamel. Acta Biomater Odontol Scand. 2016;2:102-7. https://doi.org/10.1080/23337931.2016.1222283.

7. Nair R, Bandhe S, Ganorkar OK, Saha S, Sial S, Nair A. A comparative evaluation of the three different antioxidant treatments on the bond strength of composite resin to bleached enamel: an in vitro study. J Conserv Dent. 2019;22:82-6. https://doi.org/10.4103/JCD.JCD_193_18.

8. Rana R, Kaushik M, Sharma R, Reddy P, Mehra N. Comparative evaluation of effects of natural antioxidants on the shear bond strength of composite resin to bleached enamel. Indian J Dent Res. 2019;30:112-6. https://doi.org/ 10.4103/ijdr.IJDR-397-17.

9. Carey CM. Tooth whitening: what we now know. J Evid Based Dent Pract. 2014;14:70-6. https://doi.org/10. 1016/j.jebdp.2014.02.006.

10. Kwon SR, Wertz PW. Review of the mechanism of tooth whitening. J Esthet Restor Dent. 2015;27:240-57. https:// doi.org/10.1111/jerd.12152.

11. Mushashe AM, Coelho BS, Garcia PP, Rechia do BCN, da Cunha LF, Correr GM, et al. Effect of different bleaching protocols on whitening efficiency and enamel superficial microhardness. J Clin Exp Dent. 2018;10:e772-5. https://doi.org/10.4317/jced.54967.

12. Caneppele TMF, Torres CRG, Bresciani E. Analysis of the color and fluorescence alterations of enamel and dentin treated with hydrogen peroxide. Braz Dent J. 2015;26:514-8. https://doi.org/10.1590/0103-6440201300249.

13. Alqahtani MQ. Tooth-bleaching procedures and their controversial effects: a literature review. Saudi Dent J. 2014;26:33-46. https://doi.org/10.1016/..sdenti.2014.02.002

14. Kawamoto K, Tsujimoto Y. Effects of the hydroxyl radical and hydrogen peroxide on tooth bleaching. J Endod. 2004;30:45-50. https://doi.org/10.1097/00004770-200401000-00010.

15. Gauthier MA, Stangel I, Ellis TH, Zhu XX. Oxygen inhibition in dental resins. J Dent Res. 2005;84:725-9. https:// doi.org/10.1177/154405910508400808.

16. Titley KC, Torneck CD, Smith DC, Chernecky R, Adibfar A. Scanning electron microscopy observations on the penetration and structure of resin tags in bleached and unbleached bovine enamel. J Endod. 1991;17:72-5. https://doi.org/10.1016/S0099-2399(06)81611-0.

17. Nour El-din AK, Miller BH, Griggs JA, Wakefield C. Immediate bonding to bleached enamel. Oper Dent. 2006;31:106-14. https://doi.org/10.2341/04-201.

18. Cura M, Fuentes MV, Ceballos L. Effect of low-concentration bleaching products on enamel bond strength at different elapsed times after bleaching treatment. Dent Mater J. 2015;34:203-10. https://doi.org/10.4012/dmj. 2014-248.

19. Cadenaro M, Maravic T, Comba A, Mazzoni A, Fanfoni L, Hilton T, et al. The role of polymerization in adhesive dentistry. Dent Mater. 2018;35:e1-22 (S0109564118312156).

20. Münchow EA, Bottino MC. Recent advances in adhesive bonding: the role of biomolecules, nanocompounds, and bonding strategies in enhancing resin bonding to dental substrates. Curr Oral Health Reports. 2017;4:21527. https://doi.org/10.1007/s40496-017-0146-y.

21. Yao C, Ahmed MH, Okazaki Y, Van Landuyt KL, Huang C, Van Meerbeek B. Bonding efficacy of a new self-adhesive restorative onto flat dentin vs class-I cavity-bottom dentin. J Adhes Dent. 2020;22:65-77. https://doi.org/10. 3290/j.jad.a43999

22. Kadiyala A, Saladi HK, Bollu IP, Burla D, Ballullaya SV, Devalla S, et al. Effect of different anti-oxidants on shear bond strength of composite resins to bleached human enamel. J Clin Diagnostic Res. 2015;9:ZC40-3. https:// doi.org/10.7860/JCDR/2015/16140.6790.

23. Ghaleb M, Orsini G, Putignano A, Dabbagh S, Haber G, Hardan L. The effect of different bleaching protocols, used with and without sodium ascorbate, on bond strength between composite and enamel. Materials (Basel). 2020;13:2710. https://doi.org/10.3390/ma13122710.

24. Alhasyimi AA, Pudyani PS, Hafizi I. Effect of mangosteen peel extract as an antioxidant agent on the shear bond strength of orthodontic brackets bonded to bleached teeth. Dental Press J Orthod. 2018;23:58-64. https://doi. org/10.1590/2177-6709.23.5.058-064.oar.

25. Bansal M, Kaur P, Cyriac AR, Kadian N, Jaiswal P, Rathee K. Impact of different antioxidants on the bond strength of resinbased composite on bleached enamel—an in vitro study. J Contemp Dent Pract. 2019;20:64-70. https:// doi.org/10.5005/jp-journals-10024-2477.

26. Karadas M, Demirbuga S. Influence of a short-time antioxidant application on the dentin bond strength after intracoronal bleaching. Microsc Res Tech. 2018;82:1720-7. https://doi.org/10.1002/jemt.23337.

27. Lima AF, Da Silva Fonseca FM, Freitas MS, Palialol ARM, Aguiar FHB, Marchi GM. Effect of bleaching treatment and reduced application time of an antioxidant on bond strength to bleached enamel and subjacent dentin. Adhes Dent. 2011;13:537-53742. https://doi.org/10.3290/j.jad.a19813.

28. Urban VM, Machado AL, Vergani CE, Giampaolo ET, Pavarina AC, de Almeida FG, Cass QB. Effect of water-bath post-polymerization on the mechanical properties, degree of conversion, and leaching of residual compounds of hard chairside reline resins. Dent Mater. 2009:25:662-71. https://doi.org/10.1016/j.dental.2008.10.017.

29. Armstrong S, Breschi L, Özcan M, Pfefferkorn F, Ferrari M, Van Meerbeek B. Academy of Dental Materials guidance on in vitro testing of dental composite bonding effectiveness to dentin/enamel using micro-tensile bond strength ( $\mu$ TBS) approach. Dent Mater. 2017;33:133-43. https://doi.org/10.1016/j.dental.2016.11.015.

30. Fernandes HO, Santos LB, Firoozmand LM. Shear bond strength of an orthodontic self-etching adhesive after intracoronary bleaching. Orthod Craniofacial Res. 2015;18:117-24. https://doi.org/10.1111/ocr.12067.

31. Kılınç Hİ, Aslan T, Kılıç K, Er Ö, Kurt G. Effect of delayed bonding and antioxidant application on the bond strength to enamel after internal bleaching. J Prosthodont. 2016;25:386-91. https://doi.org/10.1111/jopr.12303. 
32. Zhao H, Li X, Wang J, Qu S, Weng J, Zhang X. Characterization of peroxide ions in hydroxyapatite lattice. J Biomed Mater Res. 2000;52:157-63. https://doi.org/10.1002/1097-4636(200010)52:1\%3c157::AID-JBM20\%3e3.0. $\mathrm{CO} ; 2-\mathrm{U}$.

33. Nari-Ratih D, Widyastuti A. Effect of antioxidants on the shear bond strength of composite resin to enamel following extra-coronal bleaching. J Clin Exp Dent. 2019;11:e126-32. https://doi.org/10.4317/jced.55359.

34. Lai SCN, Tay FR, Cheung GSP, Mak YF, Carvalho RM, Wei SHY, et al. Reversal of compromised bonding in bleached enamel. J Dent Res. 2002;81:477-81. https://doi.org/10.1177/154405910208100709.

35. de Lima Neto CF, da Silva CB, da Silva MAB, Vitti RP, Zanta de CLPeS, Tonholo J (2018) Tooth whitening affects bond strength of adhesive systems in enamel. Rev Mater 23. https://doi.org/10.1590/s1517-707620180004.0561.

36. Miranda TAM, Moura SK, de Amorim VHO, Terada RSS, Pascotto RC. Influence of exposure time to saliva and antioxidant treatment on bond strength to enamel after tooth bleaching: an in situ study. J Appl Oral Sci. 2013;21:567-74. https://doi.org/10.1590/1679-775720130035.

37. Cadenaro M, Breschi L, Antoniolli F, Mazzoni A, Di Lenarda R. Influence of whitening on the degree of conversion of dental adhesives on dentin. Eur J Oral Sci. 2006;114:257-62. https://doi.org/10.1111/j.1600-0722.2006.00351.x.

38. Bittencourt BF, Dominguez JA, Loguercio AD, Gomes JC, Gomes OMM. Influence of two different methods of delivering fluoride on bond strength and degree of conversion of an adhesive after bleaching. J Adhes Dent. 2013;15:553-9. https://doi.org/10.3290/j.jad.a29585.

39. Bhusari CP, Sharma DS. Pattern of hydroxyapatite crystal growth on bleached enamel following the application of two antioxidants: an atomic force microscope study. J Clin Pediatr Dent. 2017;41:38-47. https://doi.org/10. 17796/1053-4628-41.1.38.

40. Miguel LC, Baratieri LN, Monteiro S, Ritter AV. In situ effect of $10 \%$ carbamide peroxide on resin-dentin bond strengths: a novel pilot study. J Esthet Restor Dent. 2004;16:235-41. https://doi.org/10.1111/j.1708-8240.2004. tb00042.x.

41. Da Silva JMG, Botta AC, Barcellos DC, Pagani C, Torres CRG. Effect of antioxidant agents on bond strength of composite to bleached enamel with 38\% hydrogen peroxide. Mater Res. 2011;14:235-8. https://doi.org/10. 1590/S1516-14392011005000031.

42. Arumugam M, Nesamani R, Kittappa K, Sanjeev K, Sekar M. Effect of various antioxidants on the shear bond strength of composite resin to bleached enamel: an in vitro study. J Conserv Dent. 2014;17:22-6. https://doi. org/10.4103/0972-0707.124113.

43. Cheng YL, Musonda J, Cheng H, Attin T, Zheng M, Yu H. Effect of surface removal following bleaching on the bond strength of enamel. BMC Oral Health. 2019;19:50. https://doi.org/10.1186/s12903-019-0742-4.

44. Berger SB, De Souza Carreira RP, Guiraldo RD, Lopes MB, Pavan S, Giannini M, et al. Can green tea be used to reverse compromised bond strength after bleaching? Eur J Oral Sci. 2013;121:377-81. https://doi.org/10.1111/ eos.12062.

45. Degirmenci A, Kara E, Degirmenci BU, Ozcan M. Evaluation the effect of different antioxidants applied after bleaching on teeth color stability. Brazilian Dent Sci. 2020;23:1-9. https://doi.org/10.14295/bds.2020.v23i4.2074.

46. Schwertner RCA, Leoncio JSY, Schwertner A, Guiraldo RD, Lopes MB, De Carvalho HC, Gonini-Júnior A, Berger SB. The effect of green tea on the shear strength of brackets after home whitening treatment. Appl Adhes Sci. 2016;4:12. https://doi.org/10.1186/s40563-016-0069-1.

47. Xu Y, Zhou J, Tan J. Use of grape seed extract for improving the shear bond strength of total-etching adhesive to bleached enamel. Dent Mater J. 2018;37:325-31. https://doi.org/10.4012/dmj.2017-060.

48. Castrillejo VM, Romero MM, Esteve M, Ardévol A, Blay M, Bladé C, et al. Antioxidant effects of a grapeseed procyanidin extract and oleoyl-estrone in obese Zucker rats. Nutrition. 2011;27:1172-6. https://doi.org/10.1016/j. nut.2010.12.010.

49. Wang $Y$, Chen $C$, Zang HL, Liang $Y H$. The recovery effect of proanthocyanidin on microtensile bond strength to sodium hypochlorite-treated dentine. Int Endod J. 2019;52:371-6. https://doi.org/10.1111/iej.13005.

50. Zhang H, Shao S, Du A, Wang Y, Cheng B, Zhang Z. Comparative evaluation of two antioxidants on reversing the immediate bond strength of bleached enamel: in vitro study. Med Sci Monit. 2020;26:e920481-1-e920481-8. https:// doi.org/10.12659/MSM.920481.

51. Elawsya ME, El-shehawy TM, Zaghloul NM. Influence of various antioxidants on micro-shear bond strength of resin composite to bleached enamel. J Esthet Restor Dent. 2020;33:371-9. https://doi.org/10.1111/jerd.12613.

\section{Publisher's Note}

Springer Nature remains neutral with regard to jurisdictional claims in published maps and institutional affiliations. 